\section{Supressão contralateral das emissões otoacústicas nos indivíduos com zumbido}

\author{
Mariana Lopes Fávero', Tanit Ganz Sanchez ${ }^{2}$, \\ Ricardo Ferreira Bento ${ }^{3}$, Andreia Ferreira \\ Nascimento ${ }^{4}$
}

Resumo / Summary
Palavras-chave: zumbido, condutos eferentes, lateralidade, emissões otoacústicas.

Key words: Tinnitus, Efferent pathways, Laterality, otoacoustics emissions
I ntrodução: A função do trato olivococlear medial é estudada pela supressão das emissões otoacústicas com o uso de uma estimulação contralateral e sofre influência da lateralidade do sistema nervoso central, não apresentando respostas iguais entre as orelhas. Uma disfunção neste trato pode implicar na geração do zumbido, porém isto ainda não foi confirmado. Objetivo: Estudar a supressão das emissões otoacústicas por produto de distorção em indivíduos com zumbido. Material e Método: Estudo caso-controle com 44 pessoas com zumbido, matriculadas no Ambulatório de Zumbido da Divisão de Clínica Otorrinolaringológica do Hospital das Clínicas da Universidade de São Paulo e 44 voluntários submetidos à emissão otoacústica por produto de distorção com e sem estimulação contralateral. Comparou-se os resultados das orelhas direita dos dois grupos. Resultados: Houve associação entre zumbido e ausência de supressão em todas as freqüências estudadas $(\mathrm{OR}>2,1)$. Conclusões: Houve uma correlação entre menor efetividade do trato olivococlear medial e a presença de zumbido.

\section{Contralateral suppression of otoacoustic emission in patients with tinnitus}

Otoacoustics emissions 


\section{INTRODUÇÃO}

Várias teorias têm sido postuladas nos últimos anos na tentativa de se explicar a gênese do zumbido. Uma delas relaciona uma disfunção do sistema auditivo eferente, mais especificamente do trato olivococlear medial, como fator desencadeante ou mantenedor desse sintoma ${ }^{1}$.

O trato olivococlear medial age sobre os movimentos das células ciliadas externas (CCE) provocando uma hiperpolarização através da liberação de acetilcolina na fenda sináptica ${ }^{2,3}$. Esta hiperpolarização ocorre em oposição à despolarização, induzida naturalmente pelos estímulos sonoros e mantém a membrana basilar em uma posição adequada para a transdução fiel das características do estímulo auditivó ${ }^{4}$.

Segundo muitos autores, a hiperpolarização é evidenciada pela redução da amplitude das emissões otoacústicas (EOA) com o uso de uma estimulação acústica na orelha contralateral ${ }^{5,6}$ e sofre influência da lateralidade do sistema nervoso central seguindo os padrões de predominância hemisférica ${ }^{7,8}$, não apresentando, portanto, resultados semelhantes entre as orelhas direita e esquerda de indivíduos destros.

Uma disfunção do sistema eferente leva à perda de modulação das células ciliadas externas, ou seja, deste equilíbrio entre despolarização e hiperpolarização, gerando uma atividade elétrica anormal e exacerbada que pode ser erroneamente interpretada como som pelo Sistema Nervoso Central ${ }^{1}$. Esta alteração na modulação pode ocorrer em função de uma lesão específica das células ciliadas externas, levando a uma redução dos estímulos eferentes inibitórios ${ }^{9}$, ou por uma alteração intrínseca do equilíbrio entre o componente excitatório e inibitório, com predomínio do primeiro ${ }^{10}$.

Como evidência desta disfunção, há relatos de pacientes com zumbido apresentando diminuição ou ausência de supressão das EOA durante a estimulação acústica contralateral ${ }^{11,12}$. No entanto, outros estudos não reproduziram estes resultados ${ }^{13,14}$. Nenhuma destas pesquisas considera a lateralidade do sistema nervoso como uma variável.

Diante desta controvérsia, desenvolvemos este estudo com o objetivo de avaliar a supressão das emissões otoacústicas por produto de distorção (EOAPD) com estimulação acústica contralateral em indivíduos com zumbido comparando-a com a supressão em indivíduos sem queixa auditiva.

\section{MATERIAL E MÉTODO}

O projeto foi aprovado pela Comissão de Ética do Hospital das Clínicas da Faculdade de Medicina da Universidade de São Paulo (CAPPesq, protocolo no 544/00).

Foi realizado um estudo tipo caso-controle com 88 participantes, divididos em dois grupos:
1. Grupo com zumbido (GZ), formado por 44 indivíduos com zumbido regularmente matriculados no Ambulatório de Zumbido da Divisão de Clínica Otorrinolaringológica do Hospital das Clínicas da Universidade de São Paulo. Os critérios de inclusão foram:

a. zumbido constante bilateral;

b. indivíduos destros selecionados pela versão resumida do Inventário de Edinburgh ${ }^{15}$ com idade máxima de 60 anos;

c. audiometria tonal normal bilateralmente (limiares $£ 25$ dB HL até $8000 \mathrm{~Hz}$ ), imitanciometria normal e EOAPD presentes entre 1000 e $6000 \mathrm{~Hz}$.

2. Grupo controle (GC), formado por 44 pessoas sem zumbido seguindo os mesmos critérios de inclusão que os do GZ, exceto pela presença do zumbido.

Os grupos foram pareados por idade (GZ: 46,7 anos, desvio padrão \pm 9,3 anos; GC: 46,8 anos, desvio padrão $\pm 9,5$ anos; $\mathrm{p}=0,98)$ e sexo ( 14 indivíduos - 31,8\% - eram do sexo masculino em cada grupo) e não apresentaram diferenças estatísticas de limiares audiométricos tonais e de EOAPD ( $p \geq 0,31$ e $p \geq 0,11$ respectivamente, para todas as freqüências estudadas).

Para a medida das EOAPD, foi utilizado um analisador coclear Celesta 503 (versão 3.xx) (Madsen Electronics, Taastrup, Denmark). Para a obtenção dos produtos de distorção (2F1-F2), foram usados dois tons puros na razão de $\mathrm{F} 2 / \mathrm{F} 1=1,22$, apresentados na intensidade 70 dBNPS seguindo a média geométrica de F1 e F2 através do DP-gram ou gráfico da freqüência pela amplitude. O estímulo acústico supressor usado foi um ruído branco gerado por um audiômetro Maico, modelo MA 32, via fone de ouvido TDH39 e coxim MX 41, na intensidade de 50 dBNA. Com o intuito de evitar manipulação da sonda das EOAPD, o fone foi acoplado na orelha contralateral à captação das EOAPD antes do início do teste. Apesar disto, a sonda da EOA foi sistematicamente testada antes da captação de cada série.

Foi considerada a razão sinal ruído de $6 \mathrm{~dB}$ em cada freqüência ao invés da amplitude total das EOAPD. A captação das EOAPD foi feita primeiro na ausência e após, na presença do ruído branco na orelha contralateral.

O cálculo do efeito supressor das EOAPD foi feito pela subtração da razão sinal ruído obtida sem o ruído contralateral do valor da razão sinal ruído com o uso do ruído contralateral, para cada freqüência específica. Valores positivos indicaram supressão das EOAPD e valores negativos ou zero indicaram não-supressão.

Para se medir a associação entre zumbido e ausência de supressão das EOAPD, comparamos os resultados entre as orelhas direitas dos indivíduos com zumbido e as orelhas direitas dos controles calculando-se a odd ratios (OR) para cada freqüência estudada, assim como os respectivos intervalos de confiança. $\left(\mathrm{IC}_{95 \%}\right)$.

A associação foi testada com o teste de qui-quad- 
rado de McNemar de acordo com métodos previamente descritos ${ }^{16}$. Consideramos nível de significância estatística $\mathrm{p} \leq 0,05$.

\section{RESULTADOS}

Os resultados observados entre os indivíduos com zumbido e os controles nas freqüências estudadas estão na Tabela 1. Em 1000 e 6000 Hz indivíduos com zumbido tenderam a apresentar uma menor supressão que os controles $(\mathrm{OR}=2,4 ; \mathrm{IC} 95 \%$ : 0,8 a 6,8; $\mathrm{p}=0,09$ e OR = 2,1; IC95\%: 0,9 a 4,9). No entanto, não houve diferença estatisticamente significante entre os dois grupos ( $p=0,09$ e $\mathrm{p}=0,07$, respectivamente).

Como pode se ver pelos valores de OR e p, a ausência de supressão das EOAPD em 1500 Hz, 2000 Hz, $3000 \mathrm{~Hz}$ e $4000 \mathrm{~Hz}$ esteve fortemente associada com a presença de zumbido.

\section{DISCUSSÃO}

Há muita controvérsia na literatura sobre a função das vias auditivas eferentes e o seu verdadeiro papel sobre os mecanismos auditivos dos seres humanos.

Entre as várias funções previamente atribuídas a essas vias estaria a de desencadeadora ou mantenedora dos quadros de zumbido, por alterações na modulação dos movimentos do órgão de Corti ${ }^{1,9,10}$.

Em indivíduos com zumbido unilateral já foi demonstrada uma menor supressão das EOAPD do lado do zumbido em relação à supressão do lado contralateral ${ }^{11,12}$, sugerindo uma alteração no funcionamento do sistema eferente nestes casos. No entanto, estes resultados não foram reproduzidos ${ }^{14}$ e, com uma amostra maior, uma menor supressão foi encontrada do lado contralateral ao zumbido $^{13}$, indicando uma não-concordância na literatura entre disfunção do trato olivococlear medial e zumbido.

Como o sistema auditivo está organizado em forma de rede, com vários pontos de comunicação entre o sistema aferente e eferente ${ }^{17}$ e o trato olivococlear medial opera de forma lateralizada, apresentando supressões maiores na orelha direita de indivíduos destros ${ }^{7,8}$, talvez estes resultados conflitantes nos pacientes com zumbido unilateral possam ocorrer em função da comparação dos dados obtidos nas orelhas direita e esquerda de um mesmo indivíduo ao invés do uso de um grupo controle.

Portanto, se uma disfunção eferente promove um quadro de zumbido na orelha esquerda de um indivíduo destro, a relação entre zumbido e menor supressão nesta orelha pode ficar superestimada, por que se espera que a supressão à esquerda seja menor nos destros. Da mesma

Tabela 1. Proporção da supressão das EOAPD em indivíduos com e sem zumbido.

\begin{tabular}{|c|c|c|c|c|c|}
\hline Freqüência & Zumbido & Sem Zumbido & OR & $\mathrm{IC}_{95 \%}$ & $\mathrm{p}$ \\
\hline Supressão & $15(34,1 \%)$ & $36(81,8 \%)$ & 1,0 & & \\
\hline $1500 \mathrm{~Hz}$ & & & & & $<0,001$ \\
\hline Supressão & $21(47,7 \%)$ & $37(84,1 \%)$ & 1,0 & & \\
\hline $2000 \mathrm{~Hz}$ & & & & & 0,001 \\
\hline Supressão & 17 (38,6\%) & $41(93,2 \%)$ & 1,0 & & \\
\hline Não Supressão & $27(61,4 \%)$ & $3(6,8 \%)$ & 8,0 & 1,8 a 24,8 & \\
\hline $3000 \mathrm{~Hz}$ & & & & & 0,001 \\
\hline Supressão & $13(29,6 \%)$ & $43(97,7 \%)$ & 1,0 & & \\
\hline Não Supressão & $18(40,9 \%)$ & $4(9,1 \%)$ & $¥$ & $5,5 a *$ & \\
\hline $6000 \mathrm{~Hz}$ & & & & & 0,07 \\
\hline Supressão & $23(52,3 \%)$ & $30(68,2 \%)$ & 1,0 & & \\
\hline Não Supressão & $21(47,7 \%)$ & $14(31,8 \%)$ & 2,1 & 0,9 a 4,9 & \\
\hline
\end{tabular}

$\mathrm{OR}=$ Odds ratio correspondente à análise pareada.

$\mathrm{p}=$ valor correspondente ao teste de Qui-quadrado de McNemar. 
forma, se este mesmo indivíduo desenvolver um zumbido à direita, a relação entre zumbido e menor supressão pode ser subestimada, considerando-se que a supressão é usualmente maior à direita nos destros. Diante disto, acreditamos que o uso de um grupo controle é mais apropriado para este tipo de estudo, e não a orelha contralateral de um mesmo indivíduo.

No entanto, para o uso de um grupo controle, tivemos que tomar o cuidado de parear os limiares auditivos tonais e as EOAPD entre os grupos, já que indivíduos com zumbido podem apresentar valores menores destes limiares quando comparados ao grupo controle, o que levaria a índices menores de supressão de $\mathrm{EOA}^{18,19}$.

Em um estudo anterior, nós já havíamos comparado a supressão das EOAPD nas orelhas direita de indivíduos com zumbido com a supressão das orelhas direita de controles ${ }^{20}$. Provavelmente em função do número limitado de participantes, só obtivemos uma relação significativa entre ausência de supressão das EOAPD e zumbido em $4000 \mathrm{~Hz}$.

Já neste trabalho, com uma amostra maior, observamos uma associação entre uma supressão contralateral das EOAPD ausente ou menor e presença de zumbido em todas as freqüências estudadas (OR $>2,1)$. No entanto, em 1000 e $6000 \mathrm{~Hz}$, esta associação não atingiu o nível de significância estatístico, sugerindo que um aumento ainda maior da amostra poderia comprovar a correlação entre presença de zumbido e alteração da função eferente em todas as freqüências.

Com certeza o protocolo ideal de pesquisa da função das vias auditivas eferentes ainda não foi desenvolvido e isto ocorre, provavelmente, em função das muitas variáveis a serem controladas. Deste modo, a interpretação dos resultados deve ser sempre baseada nos parâmetros usados, já que estes podem influenciar as respostas sem que haja uma relação clínica evidente para isto. No caso específico deste estudo, acreditamos que o funcionamento assimétrico do trato olivococlear medial pode alterar a análise dos resultados e que esta é uma variável que deve ser controlada.

\section{CONCLUSÕES}

Apesar do papel das vias auditivas eferentes sobre a gênese e a manutenção do zumbido ainda permanecer desconhecido, demonstramos que as pessoas com zumbido, incluídas neste trabalho, apresentaram uma alteração da função do trato olivococlear medial, vista pela menor supressão das EOAPD neste grupo quando comparada com o grupo sem queixas auditivas.

\section{REFERÊNCIAS BIBLIOGRÁFICAS}

1. Jastreboff PJ. Phantom auditory perception (Tinnitus). Mechanisms of generation and perception. Neurosci Res 1990;8:221-54.

2. Sahley TL, Nodar RH, Musiek FE. Efferent auditory system, structure and function. San Diego: Singular Publishing Group; 1997. pp.1-23.

3. Funchs P. The Synaptic physiology of cochlear hair cells. Audiol Neurootol 2002;7:40-4.

4. Ludwig J, Oliver D, Frank G, Klöcker N, Gummer AW, Fakler B. Reciprocal electromechanical properties of rat prestin: The motor molecule from rat outer hair cells. PNAS 2001;98:4178-83.

5. De Ceulaer G, Yperman M, Daemers K, Van Driessche K, Somers T, Officierss FE, Govaerts PJ. Contralateral suppression of transient evoked otoacoustic emission: Normative data for a clinical test set-up. Otol Neurotol 2001;22:350-5.

6. James AL, Mount RJ, Harrison RV. Contralateral suppression of DPOAE measured in real time. Clin Otolaryngol 2002;27:106-12.

7. Khalfa S, Collet L. Functional asymmetry of medial olivocochlear system in humans. Towards a peripheral auditory lateralization. NeuroReport 1996;7:993-6.

8. Khalfa S, Morlet T, Micheyl C, Morgon A. Evidence of peripheral hearing asymmetry in humans: clinical implications. Acta Otolaryngol 1997;(Stockh) 117:192-6.

9.Hazell J. Support for a neurophysiological model of tinnitus. In: V International Tinnitus Seminar, Proceedings 1995:51-7.

10. Robertson D, Winter IM, Mulders WHAM. Influence of descending neural pathways on responses in the mammalian cochlear nucleus. In: VII International Tinnitus Seminar, Proceedings 2002:31-3.

11. Veuillet E, Collet L, Disant F, Morgon A. Tinnitus and medial cochlear efferent system. In: IV International Tinnitus Seminar. Proceedings, 1991:205-9.

12. Chéry-Croze S, Collet L, Morgon A. Medial olivo-cochlear system and tinnitus. Acta Otolaryngol 1993; (Stockh) 113:285-90.

13. Chéry-Croze S, Moulin A, Collet L, Morgon A. Is the test of medial efferent system function a relevant investigation in tinnitus? Brit J Audiol 1994;28:13-25.

14. Lind O. Transient-evoked otoacoustic emission and contralateral suppression in patients with unilateral tinnitus. Scand Audiol 1996;25:167-72.

15. Oldfield RC. The assessment and analysis of handedness: The Edinburgh Handedness Inventory. Neuropsychologoia 1971;9:97-118.

16. Kirkwood BR. Essentials of medical statistics. Oxford: Blackwell Science Publications; 1988.

17. Fávero-Breuel ML, Sanchez TG, Bento RF. Vias auditivas eferentes e seu papel no sistema auditivo. Arq Fund Otorrinolaringol 2001;5:625.

18. Onish ET. Emissão otoacústica por produto de distorção na avaliação do zumbido. São Paulo, 1999. Dissertação (mestrado), Escola Paulista de Medicina, Universidade Federal de São Paulo.

19. Burguetti FAR, Peloggia AG, Carvalho RMM. Amplitude de emissões otoacústicas produto de distorção em indivíduos com queixa de zumbido. Rev Bras Otorrinolaringol 2002;68:883-90.

20. Fávero ML, Sanchez TG, Nascimento AF, Bento RF. A função do trato olivococlear medial em indivíduos com zumbido. Arq Otorrinolariongol 2003;7:263-7. 